\title{
Cow's milk-based beverage consumption in 1- to 4-year-olds and allergic manifestations: an RCT
}

\author{
M. V. Pontes ${ }^{1}$, T. C. M. Ribeiro ${ }^{1}$, H. Ribeiro ${ }^{1}$, A. P. de Mattos ${ }^{1}$, I. R. Almeida' ${ }^{1}$, V. M. Leal ${ }^{1}$, G. N. Cabral' ${ }^{1}$ S. Stolz ${ }^{2}$, \\ W. Zhuang ${ }^{2}$ and D. M. F. Scalabrin ${ }^{2^{*}}$
}

\begin{abstract}
Background: Nutrients such as docosahexaenoic acid (DHA), prebiotics and $\beta$-glucan have been associated with reduced incidence of respiratory illnesses and allergic manifestations (AM). Our objective was to assess if consumption of a cow's milk-based beverage with these and other nutrients supports respiratory, gastrointestinal, and skin health in otherwise well-nourished, healthy children.

Methods: In this double-blind, randomized, controlled trial, healthy children (1-4 years of age) from two daycare centers in Brazil were fed three servings/day of a cow's milk-based beverage (CMBB; $n=125)$ containing DHA, the prebiotics polydextrose (PDX) and galactooligosaccharides (GOS), $\beta$-glucan, and other key nutrients, or a control cow's milk-based beverage (control; $n=131$ ) for up to 28 weeks. Occurrence of respiratory infections, diarrheal disease and AM was assessed by study pediatricians and the number of episodes were analyzed with the Cochran-Mantel-Haenszel test and the Andersen-Gill model.

Results: The CMBB group had fewer episodes of AM, which included allergic rhinitis or conjunctivitis, wheezing, allergic cough, eczema and urticaria, compared to the control group $(p=0.021)$. The hazard ratio for increased number of episodes of AM was lower in the CMBB group compared to control (HR, 0.64; $95 \% \mathrm{Cl} 0.47-0.89 ; p=0.007)$. There was no difference in the incidence of respiratory infections and diarrheal disease between groups.

Conclusion: A cow's milk-based beverage containing DHA, PDX/GOS, and yeast $\beta$-glucan, and supplemented with micronutrients, including zinc, vitamin A and iron, when consumed 3 times/day for 28 weeks by healthy 1- to 4-yearold children was associated with fewer episodes of allergic manifestations in the skin and the respiratory tract.
\end{abstract}

Trial registration: registration number: NCT01431469

Keywords: DHA, Prebiotics, Yeast $\beta$-glucan, Allergic manifestations, Children

\section{Background}

Two leading causes of morbidity and mortality among children younger than 5 years of age are respiratory infections and diarrheal disease [1], which can be interrelated, as diarrhea increases the risk of lower respiratory infections $[1,2]$. The global rise of allergic diseases, including asthma, atopic dermatitis and allergic rhinitis, is another cause of concern in children, with a significant impact on quality of life [3-5]. Nutrition-related

\footnotetext{
* Correspondence: deolindascalabrin@gmail.com

${ }^{2}$ Mead Johnson Pediatric Nutrition Institute, Evansville, IN, USA

Full list of author information is available at the end of the article
}

factors are responsible for $11 \%$ of the total global disease burden in children younger than 5 years [6]. Children are particularly vulnerable to diet inadequacies, which can compromise various mechanisms of immune function, thereby increasing risk of infections $[7,8]$ and also of allergic diseases, since oral tolerance to antigens may be impaired [9]. A recent study in 2- to 6-year-old daycare children from all regions in Brazil showed that even those of the highest socioeconomic levels had insufficient consumption of fiber and micronutrients, including calcium and vitamins D and E [10]. A systematic review concluded that apparently well-nourished children younger than 5 years from developed countries 
have diets that are inadequate in meeting the recommendations, placing them at nutritional risk [11]. Therefore, even diets of eutrophic children have room for improvement.

There is currently no agreement on the impact of a dietary improvement in children whose nutrient intake meets minimal requirements but may not be the most effective to promote improved health outcomes. Certain nutrients support the immune system, such as longchain polyunsaturated fatty acids (LCPUFAs), especially omega-3 LCPUFAs, whose consumption has been associated with reduced allergic and/or respiratory illnesses in infants and children [12-16]. Likewise, prebiotic oligosaccharides support the immune system through stimulation of beneficial gut bacteria [17-20] and were associated with decreased respiratory infections and allergic diseases [21-24]. $\beta$-glucan, a polysaccharide derived from yeasts, fungi or bacteria, has also demonstrated immune-supporting properties $[25,26]$, with data showing protection against respiratory infections and allergy in adults and children [26-28]. In a recent randomized clinical trial in 3- to 4-year-old children attending daycare in China, we demonstrated that daily consumption of a cow's-milk based beverage (CMBB) containing a combination of nutrients including docosahexaenoic acid (DHA), the prebiotics polydextrose (PDX) and galactooligosaccharides (GOS), and yeast $\beta$-glucan, and enriched with micronutrients such as vitamin $\mathrm{A}$, zinc and iron, was associated with fewer acute respiratory infections (ARI) compared to cow's milk [29].

Our objective in the current study was to evaluate if consumption of the nutritionally enriched CMBB used in the study in China had an effect on the incidence of ARI and diarrheal disease and secondarily on allergic manifestations (AM) in a distinct population of children attending daycare in Brazil. Typically, children in China start attending daycare when they are 3 year-old whereas in Brazil children usually start at daycare when they are 1 year old or earlier. Consequently, we wanted to assess in the current study if potential outcomes associated with consumption of the CMBB are influenced by age, ethnicity, climate and/or socioeconomic status. The implication would be to allow recommendation of the CMBB to children from different parts of the world with diverse ethnic and socioeconomic status.

\section{Methods}

\section{Population}

Children ( 1 up to 4 years of age) from 2 daycare centers in Salvador, Bahia, Brazil who had been consuming cow's milk or cow's milk-based beverage for at least 48 hours prior to randomization were eligible. Exclusion criteria were: $>50 \%$ of total feedings consisting of breast milk; consumption of prebiotics or probiotics in the 15 days prior to randomization; diarrhea or ARI during the $48 \mathrm{~h}$ prior to randomization; a $\mathrm{z}$-score of weight-forheight $<-3$; or any serious concurrent illness.

Eligible children were randomly assigned to one of two study products according to a computer-generated randomization sequence provided by the study sponsor (Mead Johnson Nutrition). The next sealed randomization envelope in sequence was opened to reveal the code of the product that the participant should receive. Product labels and randomization envelopes were created to prevent unblinding and the study products were similar in odor, color, and flavor (vanilla). Due to the broad variation of ages and to adjust for any potential impact of age on outcomes, participants were stratified at randomization into 12-24 months of age or 25-48 months of age. We estimated that children in these two age-range groups would be fairly homogenous in terms of potential outcomes related to the consumption of $\mathrm{CMBB}$, including susceptibility to infections, diarrhea and AM.

The study was conducted from October 2011 to April 2012. The Federal University of Bahia Ethical Committee approved the protocol, and a parent/legal guardian provided signed informed consent prior to enrollment.

\section{Design}

In this double-blind (participants and researchers), randomized, controlled, parallel-designed, prospective trial, children were fed an experimental CMBB, according to the CODEX definition for follow-up formula [30], with $25 \mathrm{mg}$ of DHA, $1.2 \mathrm{~g}$ of a blend of PDX/GOS (1:1 ratio) and $8.7 \mathrm{mg}$ of yeast $\beta$-glucan (Wellmune WGP ${ }^{\circ}$, Biothera, Eagan, Minnesota) per serving, or an isocaloric, nonsupplemented cow's milk-based beverage (control). Study products were given three times per day for 28 weeks, as a replacement for the usual breakfast, afternoon and dinner beverages. The breakfast and afternoon servings were offered by daycare attendants and the evening serving as well as weekend and holiday's servings were offered at home by the caregiver. Each serving consisted of $40 \mathrm{~g}$ of powder mixed with $200 \mathrm{~mL}$ of water. The leftover of each serving was measured and recorded. See Table 1 for nutrient composition of study products.

\section{Outcomes}

The primary outcome was incidence of ARI and/or diarrheal disease. ARI comprised upper respiratory infections, including common cold, pharyngitis, tonsillitis, otitis media, infectious sinusitis and rhinitis, and lower respiratory infections, including pneumonia, bronchiolitis and bronchitis [31]. Diarrheal disease was defined as $\geq 3$ liquid or semi-liquid stools in $24 \mathrm{~h}$ with fever and/or vomiting and/or dehydration and compromised general status. Secondary outcomes included incidence of AM (allergic rhinitis or conjunctivitis, wheezing, allergic cough, eczema 
Table 1 Nutrient composition of study products

\begin{tabular}{|c|c|c|}
\hline Per $40 \mathrm{~g}$ serving of powder & Control & CMBB \\
\hline Energy, kcal & 180 & 180 \\
\hline Protein, $g$ & 7.3 & 7.3 \\
\hline Fat, g & 6.6 & 6.6 \\
\hline - DHA, mg & - & 25 \\
\hline Carbohydrate, g & 23 & 23 \\
\hline - Dietary fiber, g (1:1 ratio PDX/GOS) & - & 1.2 \\
\hline - Beta-1,3/1,6-glucans, mg & - & 8.7 \\
\hline Vitamin A, IU & 380 & 630 \\
\hline Vitamin D, IU & 31 & 119 \\
\hline Vitamin E, IU & 0.33 & 2.6 \\
\hline Vitamin $\mathrm{K}_{1}$, mcg & 0.41 & 9.5 \\
\hline Thiamine, mcg & 57 & 210 \\
\hline Riboflavin, mcg & 520 & 490 \\
\hline Vitamin $B_{6}, \mathrm{mcg}$ & 42 & 183 \\
\hline Vitamin $B_{12}$, mcg & 0.72 & 0.72 \\
\hline Niacin, mcg & 144 & 2200 \\
\hline Folic acid, mcg & 7.8 & 31 \\
\hline Pantothenic acid, mcg & 770 & 1160 \\
\hline Biotin, mcg & 5.4 & 4.7 \\
\hline Vitamin C, mg & 2.4 & 29 \\
\hline Choline, mg & 28 & 44 \\
\hline Calcium, mg & 280 & 290 \\
\hline Phosphorus, mg & 200 & 187 \\
\hline Magnesium, mg & 25 & 26 \\
\hline Sodium, mg & 97 & 96 \\
\hline Potassium, mg & 400 & 420 \\
\hline Chloride, mg & 330 & 320 \\
\hline lodine, mcg & 13.4 & 15.2 \\
\hline Iron, mg & 0.05 & 3.0 \\
\hline Zinc, mg & 0.72 & 2.3 \\
\hline Manganese, mcg & 5 & 19.2 \\
\hline Copper, mcg & 4.8 & 82 \\
\hline
\end{tabular}

and urticaria) [31], incidence of all adverse events, growth, stool characteristics, fecal and serum immune markers, iron and zinc status and incidence of stool parasites.

In a post hoc analysis, we compared incidence of constipation during the study in the two study groups. Constipation was defined as presence of at least two of the following for at least two uninterrupted weeks: hard stools, difficulty or pain to defecate and $\mathrm{a}>72-\mathrm{h}$ interval without defecation.

All clinical outcomes were diagnosed by study pediatricians. Participants were evaluated by study pediatricians at the pediatric office in the daycare every time a health complaint was reported, either by parents/caregivers or daycare assistants. In addition, every 4 weeks participants were routinely assessed by study pediatricians at the time of anthropometric measurements. Weight and length/height measurements were obtained during randomization and every 4 weeks thereafter and converted into z-scores based on WHO growth standards [32]. Blood and stool samples were collected at baseline and end of study to assess peripheral blood cell count, serum ferritin and zinc, immune markers by ELISA (fecal secretory IgA and serum IL-10, TGF- $\beta 1$, TGF- $\beta 2$, IL-4 and IFN- $\Upsilon$ ) and stool parasites by direct microscopy. Laboratory analyses were conducted by R\&D Systems, Minneapolis, MN, USA; Doctor's Data, St. Charles, IL, USA; and the study site's local lab.

\section{Sample size and statistics}

A sample size of 125 completed per group was needed to achieve $90 \%$ power, assuming a control group proportion of 0.5 and a test group proportion of 0.3 at an alpha level of 0.05 . Frequencies of ARI, diarrheal disease and AM were compared using the Cochran-MantelHaenszel test stratified by age category and were further analyzed using the Andersen-Gill model with recurrent events modeled under the framework of the proportional hazards assumption. Fecal sIgA and serum TGF$\beta 1$ and TGF- $\beta 2$ as well as their changes from baseline to end of study were compared using the van Elteren test stratified by age category. The Kruskal-Wallis test was used for all other serum immune markers, serum ferritin and zinc and peripheral blood counts, as well as changes in IL-10 and ferritin and zinc from baseline to end of study. Changes in peripheral blood counts were analyzed using ANCOVA, with baseline values as covariates. Stool frequency and consistency and weight- and length/ height-for-age and weight-for-length/height z-scores were analyzed using repeated measures ANOVA.

\section{Results \\ Study population and clinical outcomes}

The study enrolled 256 children (control =131; $\mathrm{CMBB}=$ 125); 2 discontinued in control and five in the $C M B B$ group. Demographic and baseline characteristics (race, age, gender distribution and weight- and length/height-for-age and weight-for-length/height $\mathrm{z}$-scores) were similar between groups. There were no growth differences between groups during the study. In both groups there was significant increase from baseline to end of study in weight- and length/height-for-age $\mathrm{z}$-scores, as well as weight-forlength/height $\mathrm{z}$-scores (females: 0.4 and 0.2 to 0.5 and 0.3 ; males: 0.4 and 0.4 to 0.5 and 0.5 , in control and CMBB, respectively; $p<0.001)$. The average daily intake of study products was not significantly different between groups over the duration of the study (12-24 months of age: control $531 \mathrm{~mL} /$ day vs. CMBB $504 \mathrm{~mL} /$ day, $p=0.32 ; 25-$ 
48 months of age: control $547 \mathrm{~mL} /$ day vs. CMBB $498 \mathrm{~mL} /$ day, $p=0.06$ ).

There was no difference in the incidence of ARI or diarrheal disease between groups. The CMBB group had fewer episodes of AM compared to control (Table 2). The hazard ratio for increased number of episodes of AM was lower in the CMBB group compared to control, with no difference for ARI or diarrheal disease (Fig. 1). There was no significant difference between groups in the hazard ratio of having at least one episode of ARI (0.93, $95 \%$ CI $0.49,1.79 ; p=0.84)$, diarrheal disease $(1.57,95 \%$ CI $0.71,3.46 ; p=0.26)$ or $\operatorname{AM}(0.61,95 \% \mathrm{CI}$ $0.36,1.04 ; p=0.07)$. Among 99 types of adverse events reported and compared between groups, only occurrence of thrush was statistically different between groups (5 cases in CMBB vs. none in control; $p=0.03$ ); 10 participants who experienced at least one serious adverse event were reported in the control vs. 2 in the CMBB group.

The CMBB group had softer stools compared with control in the first 3 months of the study $(p \leq 0.024)$. In the subgroup of children 12-24 months of age, 8 of 98 children $(8 \%)$ met the criteria for constipation. However, all were in the control group, and five of the eight (63\%) remained constipated at end of the study. In the subgroup of children 25-48 months of age, no significant difference was detected in the percentage of children who remained constipated at end of study (CMBB group $1 / 14 ; 7 \%$ vs. control group $3 / 10 ; 30 \% ; p=0.27$ ).

\section{Blood and fecal outcomes}

There were no differences between groups in any of the measured immune markers (Table 3). Additionally, no relevant differences were observed between groups for serum zinc and ferritin, hemoglobin, hematocrit, and red blood cells (Table 4); white blood cells and platelets (Table 5). According to WHO criteria (anemia: hemoglobin $<11 \mathrm{~g} / \mathrm{dL}$ ) [33], $18.04 \%$ of the overall population was anemic at baseline and $13.33 \%$ at end of study; $37.50 \%$ was iron deficient at baseline and $45.83 \%$ at end of study (iron deficiency: ferritin $<12 \mathrm{ng} / \mathrm{mL}$ ) [33], with no differences between groups. Incidence of fecal parasites detected among the 17 assessed parasites is presented in Table 6.

\section{Discussion}

In this randomized, double-blind, controlled study we demonstrated for the first time that healthy 1- to 4-yearold children who consumed a CMBB with DHA, PDX/ GOS and yeast $\beta$-glucan for 28 weeks had fewer AM episodes compared to children who consumed an unfortified, cow's milk-based beverage. No effect on ARI or diarrheal disease was associated with consumption of the CMBB.

These results are consistent with studies linking protection against AM with LCPUFAs [12, 34], prebiotics $[21,22,35]$ and $\beta$-glucan $[28,36,37]$. Dietary LCPUFAs were associated with less atopic dermatitis and wheezing [12, 34], and amelioration of symptoms in asthmatic children [38]. Likewise, prebiotics have been associated with reduced incidence of atopic dermatitis, wheezing and allergic rhinitis [21, 35]. $\beta$-glucan was shown to alleviate symptoms of asthma in children when injected subcutaneously for 8 weeks [39] and symptoms of allergic rhinitis in adults $[28,36,37]$. In an RCT, adults with seasonal allergic rhinitis receiving $\beta$-glucan $250 \mathrm{mg} /$ day orally for 4 weeks had reduced nasal and eye symptoms compared with a group who received placebo [28]. Additionally, vitamin D deficiency has been correlated with respiratory allergy [40], thus the addition of vitamin $\mathrm{D}$ to the CMBB could have contributed to our results. Future studies may identify the contribution of individual nutrients to the present findings.

LCPUFAs modulate some aspects of the innate and adaptive immune systems via different mechanisms, affecting cell membrane fluidity, membrane receptors and signaling pathways. DHA can prevent NF-kB

Table 2 Frequency of episodes of illness during the 28-week study period

\begin{tabular}{|c|c|c|c|c|c|c|c|}
\hline & \multicolumn{5}{|c|}{ Number of episodes } & \multirow[b]{2}{*}{$>5$} & \multirow[t]{2}{*}{$p$-value* } \\
\hline & None & 1 & 2 & 3 & 4 & & \\
\hline \multicolumn{8}{|c|}{ Acute respiratory infections (ARI) } \\
\hline Control; n (\%) & $25(19)$ & $40(31)$ & $28(21)$ & $21(16)$ & $10(8)$ & $7(5)$ & 0.938 \\
\hline CMBB; n (\%) & $25(20)$ & $40(32)$ & $24(19)$ & $16(13)$ & $14(11)$ & $6(5)$ & \\
\hline \multicolumn{8}{|l|}{ Diarrheal disease } \\
\hline Control; n (\%) & $119(91)$ & $11(8)$ & $0(0)$ & $1(1)$ & - & - & 0.354 \\
\hline CMBB; n (\%) & $108(86)$ & $15(12)$ & $2(2)$ & $0(0)$ & - & - & \\
\hline \multicolumn{8}{|c|}{ Allergic manifestations (AM) } \\
\hline Control; n (\%) & $71(54)$ & $30(23)$ & $19(15)$ & $10(8)$ & $1(1)$ & - & 0.021 \\
\hline CMBB; n (\%) & $81(65)$ & $28(22)$ & $12(10)$ & $3(2)$ & $1(1)$ & - & \\
\hline
\end{tabular}

*Statistical analysis used Cochran-Mantel-Haenszel test adjusted for age category 


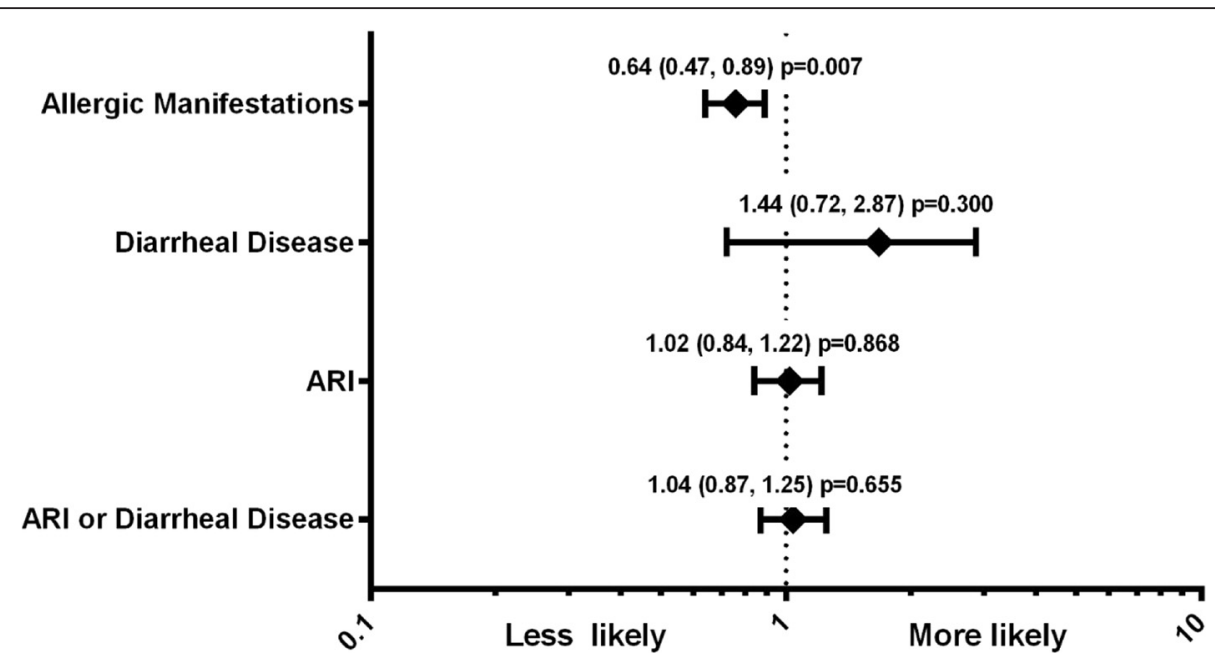

Fig. 1 Hazard ratios (95\% Cl) for increased number of episodes of illness using Andersen-Gill model adjusted for age category (12-24 or 25-48 months) and compared to control. ARI = acute respiratory infections

Table 3 Comparison of immune markers between study groups

\begin{tabular}{|c|c|c|c|}
\hline Variable $^{a}$ & Control median $\left(\mathrm{IQR}^{\mathrm{b}}\right)$ & CMBB median $\left(\mathrm{IQR}^{\mathrm{b}}\right)$ & $p$-value* \\
\hline \multicolumn{4}{|c|}{ Fecal Secretory lgA, mg/dL } \\
\hline Baseline & $102(12-226)$ & $67(7-228)$ & 0.975 \\
\hline Week 28 & $45(8-183)$ & $32(6-153)$ & 0.452 \\
\hline Baseline to Week 28 & $-1(-110-28)$ & $-5(-131-24)$ & 0.664 \\
\hline \multicolumn{4}{|l|}{$\mathrm{IL}-10, \mathrm{pg} / \mathrm{mL}$} \\
\hline Baseline & $19.1(11.9-27.5)$ & $17.3(12.0-27.6)$ & 0.760 \\
\hline Week 28 & $13.9(9.1-18.6)$ & $13.6(9.8-19.1)$ & 0.771 \\
\hline Baseline to Week 28 & $-4.9(-13.0-3.0)$ & $-.39(-12.0-0.0)$ & 0.827 \\
\hline \multicolumn{4}{|l|}{ TGF- $\beta 1, p g / m L$} \\
\hline Baseline & 20572 (15943-25641) & 22386 (17161-29081) & 0.109 \\
\hline Week 28 & 29133 (22432-35466) & 29131 (22010-37532) & 0.957 \\
\hline Baseline to Week 28 & 7863 (2569-14178) & $6351(-1346-12472)$ & 0.132 \\
\hline \multicolumn{4}{|l|}{ TGF- $\beta 2, p g / \mathrm{mL}^{\mathrm{c}}$} \\
\hline Baseline & 344.1 (252.9-479.8) & $326.0(\leq 262.2-461.7)$ & 0.801 \\
\hline Week 28 & $438.1(296.7-600.2)$ & $414.5(\leq 331.0-586.3)$ & 0.602 \\
\hline Baseline to Week 28 & $48.7(0-123)$ & $48.7(0-125)$ & 0.465 \\
\hline \multicolumn{4}{|l|}{$\mathrm{IL}-4, \mathrm{pg} / \mathrm{mL}^{\mathrm{d}}$} \\
\hline Baseline & $<1.6(<1.6-<1.6)$ & $<1.6(<1.6-<1.6)$ & 0.305 \\
\hline Week 28 & $<1.6(<1.6-<1.6)$ & $<1.6(<1.6-<1.6)$ & 0.305 \\
\hline \multicolumn{4}{|l|}{$\mid F N-\Upsilon, p g / m L^{d}$} \\
\hline Baseline & $<15.6(<15.6-<15.6)$ & $<15.6(<15.6-<15.6)$ & 0.368 \\
\hline Week 28 & $<15.6(<15.6-<15.6)$ & $<15.6(<15.6-<15.6)$ & 0.378 \\
\hline
\end{tabular}

${ }^{\mathrm{a} A l l}$ markers except fecal secretory $\lg \mathrm{A}$ were measured in serum

${ }^{\mathrm{b}} \mathrm{IQR}=25-75 \%$ interquartile range

${ }^{c} 28 \%$ of samples were under the detection limit

${ }^{\mathrm{d} C h a n g e s ~ f r o m ~ b a s e l i n e ~ t o ~ w e e k ~} 28$ were not analyzed because most of the samples were under detection limit

*Van Elteren test stratified by age category was used for fecal secretory IgA, TGF- $\beta 1$ and TGF- $\beta 2$; Kruskal-Wallis test was used for all other immune markers 
Table 4 Comparison of zinc, iron and red blood cell status between study groups

\begin{tabular}{|c|c|c|c|}
\hline Variable & Control median $\left(\mathrm{IQR}^{\mathrm{a}}\right)$ & CMBB median (IQR $\left.{ }^{\mathrm{a}}\right)$ & $p$-value \\
\hline \multicolumn{4}{|l|}{ Serum Zinc, $\mu \mathrm{mol} / \mathrm{L}$} \\
\hline Baseline & $21.4(17.6-25.4)$ & $21.8(17.2-25.9)$ & 0.793 \\
\hline Week 28 & $24.4(20.5-29.5)$ & $24.6(20.2-28.2)$ & 0.648 \\
\hline Baseline to Week 28 & $3.2(-1.0-8.0)$ & $3.3(-2.0-8.0)$ & 0.820 \\
\hline \multicolumn{4}{|l|}{ Serum Ferritin, ng/mL ${ }^{b}$} \\
\hline Baseline & $16.4(<10-26.2)$ & $14.8(<10-21.8)$ & 0.413 \\
\hline Week 28 & $13.5(<10-19.6)$ & $13.3(<10-21.8)$ & 0.863 \\
\hline Baseline to Week 28 & $-2.2(-10.0-3.0)$ & $0.0(-7.0-6.0)$ & 0.148 \\
\hline \multicolumn{4}{|l|}{ Hemoglobin, g/dL } \\
\hline Baseline & $11.8(11.2-12.3)$ & $11.7(11.1-12.3)$ & 0.432 \\
\hline Week 28 & $12.0(11.4-12.6)$ & $11.9(11.4-12.5)$ & 0.595 \\
\hline Baseline to Week $28^{c}$ & $0.26(0.1)$ & $0.30(0.1)$ & 0.561 \\
\hline \multicolumn{4}{|l|}{ Hematocrit, \% } \\
\hline Baseline & $35.5(34.0-37.1)$ & $35.3(33.8-37.2)$ & 0.560 \\
\hline Week 28 & $35.1(33.0-36.9)$ & $34.9(33.4-36.8)$ & 0.736 \\
\hline Baseline to Week $28^{c}$ & $-0.41(0.2)$ & $0.32(0.2)$ & 0.747 \\
\hline \multicolumn{4}{|l|}{ Red Blood Cells, $\times 10^{9} / \mathrm{mL}$} \\
\hline Baseline & $4.6(4.4-4.8)$ & $4.6(4.4-4.8)$ & 0.678 \\
\hline Week 28 & $4.6(4.3-4.7)$ & $4.5(4.2-4.8)$ & 0.200 \\
\hline Baseline to Week $28^{c}$ & $-0.05(0.0)$ & $-0.12(0.00)$ & 0.024 \\
\hline
\end{tabular}

${ }^{\mathrm{a}} \mathrm{IQR}=25-75 \%$ interquartile range

${ }^{\mathrm{b}} 26 \%$ of the samples were at or under the detection limit

'Changes from baseline to study week 28 were analyzed using analysis of covariance (ANCOVA), with baseline values as covariate; the values listed are adjusted mean (SE)

*Kruskal-Wallis test was used for all variables except the ones described in footnote $c$

Table 5 Comparison of white blood cells and platelets between study groups

\begin{tabular}{|c|c|c|c|}
\hline Variable & Control median (IQR $\left.{ }^{\mathrm{a}}\right)$ & CMBB median $\left(\mathrm{IQR}^{\mathrm{a}}\right)$ & $p$-value \\
\hline \multicolumn{4}{|l|}{ White Blood Cells, $\times 10^{6} / \mathrm{mL}$} \\
\hline Baseline & $9.7(7.5-11.4)$ & $9.1(7.3-11.6)$ & 0.471 \\
\hline Week 28 & $8.3(7.2-10.6)$ & $8.5(7.2-10.1)$ & 0.710 \\
\hline Baseline to Week $28^{\mathrm{b}}$ & $-0.95(0.2)$ & $-0.75(0.2)$ & 0.565 \\
\hline \multicolumn{4}{|l|}{ Neutrophils, \% } \\
\hline Baseline & $41.0(29.5-49.5)$ & $36.4(28.4-45.5)$ & 0.069 \\
\hline Week 28 & $38.8(28.9-47.2)$ & $37.2(29.9-45.3)$ & 0.371 \\
\hline Baseline to Week $28^{\mathrm{b}}$ & $0.25(1.0)$ & $-0.57(1.1)$ & 0.578 \\
\hline \multicolumn{4}{|l|}{ Lymphocytes, \% } \\
\hline Baseline & $45.7(35.0-55.7)$ & $50.9(40.2-58.0)$ & 0.028 \\
\hline Week 28 & $47.1(37.6-56.3)$ & $48.3(40.8-56.5)$ & 0.230 \\
\hline Baseline to Week $28^{\mathrm{b}}$ & $-0.26(1.0)$ & $0.99(1.0)$ & 0.390 \\
\hline \multicolumn{4}{|l|}{ Platelets, $\times 10^{6} / \mathrm{mL}$} \\
\hline Baseline & $341(286-401)$ & $345.5(301.5-400.5)$ & 0.760 \\
\hline Week 28 & $315(266-369)$ & $311(263-367)$ & 0.771 \\
\hline Baseline to Week $28^{\mathrm{b}}$ & $-3.9(0.77)$ & $-3.7(.82)$ & 0.837 \\
\hline
\end{tabular}

${ }^{\mathrm{a}} \mathrm{IQR}=25-75 \%$ interquartile range

${ }^{b}$ Changes from baseline to study week 28 were analyzed using analysis of covariance (ANCOVA), with baseline values as covariate; the values listed are adjusted mean (SE) *Kruskal-Wallis test was used for baseline and study week 28 values of all variables in this table 
Table 6 Incidence of fecal parasites at baseline and study week 28 in the overall population ${ }^{a}$

\begin{tabular}{|c|c|c|}
\hline Type of parasite & $\begin{array}{l}12-24 \text { months } \\
\text { of age } n(\%)\end{array}$ & $\begin{array}{l}25-48 \text { months } \\
\text { of age } n(\%)\end{array}$ \\
\hline \multicolumn{3}{|c|}{ Giardia duodenalis } \\
\hline Baseline & $21(21.6)$ & $38(24.4)$ \\
\hline Week 28 & $36(37.9)$ & $37(25.7)$ \\
\hline \multicolumn{3}{|c|}{ Blastocystis hominis } \\
\hline Baseline & $2(2.1)$ & $4(2.6)$ \\
\hline Week 28 & $6(6.3)$ & $7(4.9)$ \\
\hline \multicolumn{3}{|l|}{ Endolimax nana } \\
\hline Baseline & $0(0)$ & $9(5.8)$ \\
\hline Week 28 & $5(5.3)$ & $4(2.8)$ \\
\hline \multicolumn{3}{|l|}{ Entamoeba coli } \\
\hline Baseline & $0(0)$ & $7(4.5)$ \\
\hline Week 28 & $0(0)$ & $8(5.6)$ \\
\hline \multicolumn{3}{|c|}{ Ascaris lumbricoides } \\
\hline Baseline & $1(1.0)$ & $3(1.9)$ \\
\hline Week 28 & $0(0)$ & $4(2.8)$ \\
\hline \multicolumn{3}{|l|}{ Trichuris trichiura } \\
\hline Baseline & $0(0)$ & $3(1.9)$ \\
\hline Week 28 & $0(0)$ & $4(2.8)$ \\
\hline \multicolumn{3}{|c|}{ Cryptosporidium sp. } \\
\hline Baseline & $3(3.1)$ & $0(0)$ \\
\hline Week 28 & $0(0)$ & $0(0)$ \\
\hline \multicolumn{3}{|c|}{ Entamoeba histolytica } \\
\hline Baseline & $0(0)$ & $0(0)$ \\
\hline Week 28 & $0(0)$ & $1(0.7)$ \\
\hline
\end{tabular}

${ }^{a}$ Participants from both study groups combined. Participants who were symptomatic as per physician's evaluation received anti-parasite treatment during the study

activation with consequent decrease in production of IgE and pro-inflammatory cytokines that initiate and prolong allergic reactions [41]. DHA metabolites such as resolvins and protectins also act to limit inflammation [42]. Prebiotics, through stimulation of gut bacteria, may cause skewing of the perinatal allergy-prone Th2 milieu towards a balanced Th1 immune pathway [43]. $\beta$-glucan polysaccharides may also induce anti-allergic mechanisms [44]. In asthmatic children, $\beta$-glucan promoted an increase of IL-10 cytokine [39], which can inhibit Th2 mediators and allergic inflammation [45]. Interestingly, higher exposure to microbial components endotoxin and $\beta$-glucan was associated with decreased risk of sensitization to inhalant allergens, in accordance with the hygiene hypothesis [46].

Similar to the study in China [29], there was no effect on diarrheal disease in the current study. Additionally, we found no effect of CMBB on ARI in the Brazilian cohort, in contrast to the study in China in which the
CMBB group had fewer episodes of ARI and just one case of AM in the whole study population [29]. Several factors could explain the different results. The diverse racial and genetic backgrounds of the two populations may have differently affected the impact of the various nutrients of the CMBB on the immune system. The International Study of Asthma and Allergies in Childhood (ISAAC) Phase Three trial reported low prevalence of asthma and wheezing in the Asia-Pacific region and high prevalence in Latin America [47] and Brazil is among the countries with the highest prevalence of asthma [48]. Repeated episodes of ARI were more frequent in the Brazil study, likely due to the younger age (1-4 years vs. 3-4 years in China) and predisposing conditions linked to lower socioeconomic level in the Brazil cohort.

The combined prevalence of Ascaris lumbricoides and Trichuris trichiura in our study (up to $5.6 \%$ in the 2- to 4 year-olds at study week 28) is similar to the $5.4 \%$ prevalence of these helminths reported in children attending daycare in Salvador, Brazil [49] and lower than the prevalence reported in daycare children in São Paulo (13\%) [50]. However, the prevalence of Giardia duodenalis in our study (up to $26 \%$ in the 2- to 4-year-olds at study week 28) was higher than the prevalence of Giardia in those two studies $[49,50]$. Intestinal parasites may have contributed to the high incidence of AM in our cohort, as suggested in a large survey in Brazilian children $<5$ years [51], including Giardia, which was shown to be a risk factor for allergy [52].

Five children in the CMBB group, corresponding to $2 \%$ of the overall population, were diagnosed with thrush; one of them had varicella and one had been on a recent course of antibiotic, both potential risk factors for thrush [53]. High rates of colonization with Candida are reported in healthy children, $12.5 \%$ in 2 year-olds [54] and $45 \%$ in 3 to 5 year-olds [55]. We found an incidence of thrush of $2.4 \%$ in a previous study evaluating an experimental cow's milk-based beverage in one of the daycare centers of the current study [56], corresponding to three cases in the control group and suggesting that thrush is not uncommon in that population of daycare children.

In the first 3 months of the study, the CMBB group had softer stools compared with control. We previously demonstrated that daycare children of a similar age receiving a CMBB with the same prebiotic blend used in this study had softer and more frequent stools [56]. There are very limited data on the role of prebiotics to alleviate constipation in young children [57]. In the current study, no conclusions can be made regarding the incidence of constipation in the 12- to 24- month age group, since no one in this group receiving the $\mathrm{CMBB}$ met the criteria for constipation in the post hoc analysis. In the small number of participants who met the criteria 
for constipation in the 25- to 48- month age group, fewer children receiving $\mathrm{CMBB}$ remained constipated at end of study than control, although the difference was not statistically significant.

An increase in weight and length/height z-scores from baseline to end of study was observed in both groups but there were no differences in growth between the two groups. According to standard criteria to diagnose malnutrition [58], none of the children were malnourished at enrollment. Inadequate adherence to dietary guidelines has been identified in apparently well-nourished children $<5$ years of age [11]. Moreover, young children consuming unfortified cow's milk were found to be at increased risk of insufficient intake of various nutrients, including iron and vitamin $\mathrm{D}$, compared with those consuming a fortified $C M B B[59,60]$. These data suggest that the use of a CMBB such as the one in this study may be justified to correct inadequate nutrient intake leading to hidden nutritional deficiencies that can impact a child's health and development in the absence of an effect on growth. Iron deficiency, for instance, can lead to decreased cognitive function even in the absence of anemia [61]. Additionally, some nutrient deficiencies such as zinc deficiency impair normal appetite prompting a vicious circle; thus correction of the deficiency helps establish an adequate eating pattern [62].

There were no differences between groups in zinc and iron status at onset and end of study, with an incidence of anemia in the overall population of 18 and $13 \%$, at baseline and end of study, respectively. Reported prevalence of anemia in Brazil reached $47 \%$ in children $<5$ years of age, affecting all income strata but being higher in the poorest ones [63]. Participants in our study spent all weekdays at the daycare, receiving a high standard of dietary care, which likely contributed to the low incidence of anemia. Our findings are consistent with data showing a positive association between daycare attendance and hemoglobin level [64], which points to daycare attendance as protective against anemia.

The strengths of the current study include confirmation of diagnosis of ARI, diarrheal disease and AM as well as adverse events by experienced study pediatricians, close monitoring of the children at the daycare on a daily basis and meticulous assessment of intake of study formula. A weakness of the study is the inclusion of four immune active components and increased amount of minerals and vitamins in an experimental formula compared to a control formula without those improvements, which does not allow attributing the benefits of the experimental formula to individual components.

\section{Conclusion}

In this study, regular consumption of a cow's milk-based beverage containing DHA, PDX/GOS, and yeast $\beta$ glucan, and supplemented with micronutrients including zinc, vitamins $\mathrm{A}$ and $\mathrm{D}$, and iron promoted improved immune outcomes, with fewer episodes of allergic manifestations in the skin and the respiratory tract in young children. These outcomes are highly relevant for a child's overall health and physical, cognitive, psychological and social development and may contribute to the quality of life of the whole family, potentially decreasing school absenteeism, thus allowing less disruption on the lives of working parents. They may also have a direct economical impact linked to the cost of treating AM episodes, for parents and the health care system, and those costs likely surpass the cost of providing $C M B B$ to the child.

Naturally occurring prebiotics, $\beta$-glucan and DHA are usually present in normal diet but their levels vary according to the quality of the diet and may not be sufficient to promote measurable health benefits. A CMBB such as the one used in this study may be of benefit in increasing the intake of such nutrients and correcting nutritional deficiencies that can affect immune function. We propose that a CMBB should be consumed in the context of a healthy, balanced diet. Since this is the first study showing a benefit of this $\mathrm{CMBB}$ on allergic manifestations in healthy young children, additional studies are warranted to confirm the current results and reinforce the recommendation of this formula to help reducing allergic manifestations.

\section{Ethics approval}

The Research Ethics Committee of the University Hospital Complex Professor Edgard Santos, Federal University of Bahia, Brazil, and the National Research Ethics Committee (CONEP) approved this project on April 4, 2011 (NO. 76/ 2009).

\section{Abbreviations \\ AM: Allergic manifestation(s); ANCOVA: Analysis of covariance; ANOVA: Analysis of variance; ARI: Acute respiratory infection(s); CMBB: Cow's milk-based bever- age; DHA: Docosahexaenoic acid; GOS: Galactooligosaccharides; IFN: Interferon; Ig: Immunoglobulin; IL: Interleukin; LCPUFAs: Long-chain polyunsaturated fatty acids; NF: Nuclear factor; PDX: Polydextrose; RCT: Randomized controlled trial; TGF: Tumor growth factor.}

\section{Competing interest}

Dr. Scalabrin, S. Stolz and W. Zhuang work in Clinical Research, Department of Medical Affairs at Mead Johnson Nutrition. All of the remaining authors have no competing interest to disclose.

\section{Authors' contributions}

MVP conceptualized and designed the study, coordinated data collection and analysis, reviewed and revised the manuscript, and approved the final manuscript. TCMR conceptualized and designed the study, supervised and coordinated data collection and analysis, interpreted the data, reviewed and revised the manuscript, and approved the final manuscript. HR conceptualized and designed the study, supervised data collection, interpreted the data, reviewed and revised the manuscript, and approved 
the final manuscript. APdeM conceptualized and designed the study, coordinated data collection, reviewed and revised the manuscript, and approved the final manuscript. IRA participated in data collection, reviewed and revised the manuscript, and approved the final manuscript. VML participated in data collection, reviewed and revised the manuscript, and approved the final manuscript. GNC participated in data collection, reviewed and revised the manuscript, and approved the final manuscript. SS conceptualized and designed the study, monitored data collection, reviewed and revised the manuscript, and approved the final manuscript. WZ analyzed and interpreted the data, reviewed and revised the manuscript, and approved the final manuscript. DMFS conceptualized and designed the study, analyzed and interpreted the data, reviewed and revised the manuscript, and approved the final manuscript.

\section{Acknowledgements}

We thank the children and parents who participated in the study, the coordinators of the daycares, Clese Cerqueira and Lícia Valente, and the daycare staff for their collaboration. We thank Paul Strong, PhD for writing assistance, and Cheryl Harris, MS for assistance with the statistical analysis/interpretation.

\section{Funding source}

This study was funded by Mead Johnson Nutrition.

\section{Financial disclosure}

The study products were provided by Mead Johnson Nutrition. Dr. Scalabrin, S. Stolz, and W. Zhuang work in Clinical Research, Department of Medical Affairs at Mead Johnson Nutrition. All of the remaining authors have no financial relationships to disclose.

\section{Author details}

${ }^{1}$ Federal University of Bahia, Salvador, Bahia, Brazil. ${ }^{2}$ Mead Johnson Pediatric Nutrition Institute, Evansville, IN, USA.

Received: 10 November 2015 Accepted: 18 February 2016 Published online: 27 February 2016

\section{References}

1. Liu L, Oza S, Hogan D, Perin J, Rudan I, Lawn JE, Cousens S, Mathers C, Black RE. Global, regional, and national causes of child mortality in 2000-13, with projections to inform post-2015 priorities: an updated systematic analysis. Lancet. 2014;385:430-40.

2. Walker CL, Perin J, Katz J, Tielsch JM, Black RE. Diarrhea as a risk factor for acute lower respiratory tract infections among young children in low income settings. J Glob Health. 2013;3:010402.

3. Asher MI, Montefort S, Bjorksten B, Lai CK, Strachan DP, Weiland SK, Williams H. Worldwide time trends in the prevalence of symptoms of asthma, allergic rhinoconjunctivitis, and eczema in childhood: ISAAC phases one and three repeat multicountry cross-sectional surveys. Lancet. 2006;368:733-43.

4. Sicherer SH, Noone SA, Munoz-Furlong A. The impact of childhood food allergy on quality of life. Ann Allergy Asthma Immunol. 2001;87:461-4.

5. Meltzer EO. Quality of life in adults and children with allergic rhinitis. J Allergy Clin Immunol. 2001;108:S45-53.

6. Black RE, Allen LH, Bhutta ZA, Caulfield LE, de Onis M, Ezzati M, Mathers C, Rivera J. Maternal and child undernutrition: global and regional exposures and health consequences. Lancet. 2008;371:243-60.

7. Rytter MJ, Kolte L, Briend A, Friis H, Christensen VB. The immune system in children with malnutrition-a systematic review. PLoS One. 2014;9:e105017.

8. Cunningham-Rundles S, McNeeley DF, Moon A. Mechanisms of nutrient modulation of the immune response. J Allergy Clin Immunol. 2005:115:1119-28. quiz 1129.

9. Campbell DI, Murch SH, Elia M, Sullivan PB, Sanyang MS, Jobarteh B, Lunn PG. Chronic T cell-mediated enteropathy in rural West African children: relationship with nutritional status and small bowel function. Pediatr Res 2003;54:306-11.

10. Bueno MB, Fisberg RM, Maximino P, Rodrigues Gde P, Fisberg M. Nutritional risk among Brazilian children 2 to 6 years old: a multicenter study. Nutrition. 2013;29:405-10.

11. Smithers LG, Golley RK, Brazionis L, Lynch JW. Characterizing whole diets of young children from developed countries and the association between diet and health: a systematic review. Nutr Rev. 2011;69:449-67.
12. Birch EE, Khoury JC, Berseth CL, Castaneda YS, Couch JM, Bean J, Tamer R, Harris $\mathrm{CL}$, Mitmesser SH, Scalabrin DM. The impact of early nutrition on incidence of allergic manifestations and common respiratory illnesses in children. J Pediatr. 2010;156:902-6. 906 e901.

13. Lapillonne A, Pastor N, Zhuang W, Scalabrin DM. Infants fed formula with added long chain polyunsaturated fatty acids have reduced incidence of respiratory illnesses and diarrhea during the first year of life. BMC Pediatr. 2014;14:168.

14. Thienprasert A, Samuhaseneetoo S, Popplestone K, West AL, Miles EA, Calder PC. Fish oil n-3 polyunsaturated fatty acids selectively affect plasma cytokines and decrease illness in Thai schoolchildren: a randomized, doubleblind, placebo-controlled intervention trial. J Pediatr. 2009;154:391-5.

15. Minns LM, Kerling EH, Neely MR, Sullivan DK, Wampler $J$, Harris $C L$, Berseth $C L$, Carlson SE. Toddler formula supplemented with docosahexaenoic acid (DHA) improves DHA status and respiratory health in a randomized, double-blind, controlled trial of US children less than 3 years of age. Prostaglandins Leukot Essent Fatty Acids. 2010;82:287-93.

16. Hageman JH, Hooyenga P, Diersen-Schade DA, Scalabrin DM, Wichers HJ, Birch EE. The impact of dietary long-chain polyunsaturated fatty acids on respiratory illness in infants and children. Curr Allergy Asthma Rep. 2012:12:564-73.

17. Fanaro S, Marten B, Bagna R, Vigi V, Fabris C, Pena-Quintana L, Arguelles F, Scholz-Ahrens KE, Sawatzki G, Zelenka R, et al. Galacto-oligosaccharides are bifidogenic and safe at weaning: a double-blind randomized multicenter study. J Pediatr Gastroenterol Nutr. 2009:48:82-8.

18. Scalabrin DM, Mitmesser SH, Welling GW, Harris CL, Marunycz JD, Walker DC, Bos NA, Tolkko S, Salminen S, Vanderhoof JA. New prebiotic blend of polydextrose and galacto-oligosaccharides has a bifidogenic effect in young infants. J Pediatr Gastroenterol Nutr. 2012;54:343-52.

19. Scholtens PA, Alliet P, Raes M, Alles MS, Kroes H, Boehm G, Knippels LM, Knol J, Vandenplas $Y$. Fecal secretory immunoglobulin $A$ is increased in healthy infants who receive a formula with short-chain galacto-oligosaccharides and long-chain fructo-oligosaccharides. J Nutr. 2008;138:1141-7.

20. Giovannini M, Verduci E, Gregori D, Ballali S, Soldi S, Ghisleni D, et al. Prebiotic effect of an infant formula supplemented with galactooligosaccharides: randomized multicenter trial. J Am Coll Nutr. 2014;33:385-93

21. Arslanoglu S, Moro GE, Boehm G, Wienz F, Stahl B, Bertino E. Early neutral prebiotic oligosaccharide supplementation reduces the incidence of some allergic manifestations in the first 5 years of life. J Biol Regul Homeost Agents. 2012;26:49-59.

22. Osborn DA, Sinn JK. Prebiotics in infants for prevention of allergy. Cochrane Database Syst Rev. 2013;3:CD006474.

23. Luoto R, Ruuskanen O, Waris M, Kalliomaki M, Salminen S, Isolauri E. Prebiotic and probiotic supplementation prevents rhinovirus infections in preterm infants: A randomized, placebo-controlled trial. J Allergy Clin Immunol. 2014;133:405-13.

24. Chatchatee P, Lee WS, Carrilho E, Kosuwon P, Simakachorn N, Yavuz Y, Schouten B, Graaff PL, Szajewska H. Effects of growing-up milk supplemented with prebiotics and LCPUFAs on infections in young children. J Pediatr Gastroenterol Nutr. 2014:58:428-37.

25. Jesenak M, Hrubisko M, Majtan J, Rennerova Z, Banovcin P. Anti-allergic effect of Pleuran (beta-glucan from Pleurotus ostreatus) in children with recurrent respiratory tract infections. Phytother Res. 2014;28:471-4.

26. Jesenak M, Majtan J, Rennerova Z, Kyselovic J, Banovcin P, Hrubisko M. Immunomodulatory effect of pleuran (beta-glucan from Pleurotus ostreatus) in children with recurrent respiratory tract infections. Int Immunopharmacol. 2013:15:395-9.

27. Auinger A, Riede L, Bothe G, Busch R, Gruenwald J. Yeast (1,3)-(1,6)-betaglucan helps to maintain the body's defence against pathogens: a doubleblind, randomized, placebo-controlled, multicentric study in healthy subjects. Eur J Nutr. 2013;52(8):1913-8.

28. Talbott SM, Talbott JA, Talbott TL, Dingler E. Beta-glucan supplementation, allergy symptoms, and quality of life in self-described ragweed allergy sufferers. Food Sci Nutr. 2013;1:90-101.

29. Li F, Jin X, Liu B, Zhuang W, Scalabrin D. Follow-up formula consumption in 3- to 4-year-olds and respiratory infections: an RCT. Pediatrics. 2014;133:e1533-1540.

30. CODEX. Codex standard for follow-Up formula: codex stan 156-1987. Geneva: Codex; 1987.

31. Kliegman RM, Stanton BF, Schor NF, St. Geme JW, Behrman RE. Nelson Textbook of Pediatrics. 19 $9^{\text {th }}$ ed. Philadelphia, PA: Elsevier Saunders; 2011. 
32. WHO Multicentre Growth Reference Study Group. WHO Child Growth Standards based on length/height, weight and age. Acta Paediatr Suppl. 2006;450:76-85.

33. World Health Organization. Iron deficiency anaemia: assessment, prevention and control: a guide for programme managers. Geneva: WHO/NHD/013; 2001.

34. D'Vaz N, Meldrum SJ, Dunstan JA, Martino D, McCarthy S, Metcalfe J, Tulic MK, Mori TA, Prescott SL. Postnatal fish oil supplementation in high-risk infants to prevent allergy: randomized controlled trial. Pediatrics. 2012;130:674-82

35. Gruber C, van Stuijvenberg M, Mosca F, Moro G, Chirico G, Braegger CP, Riedler J, Boehm G, Wahn U. Reduced occurrence of early atopic dermatitis because of immunoactive prebiotics among low-atopy-risk infants. J Allergy Clin Immunol. 2010;126:791-7.

36. Moyad MA, Robinson LE, Kittelsrud JM, Reeves SG, Weaver SE, Guzman Al, Bubak ME. Immunogenic yeast-based fermentation product reduces allergic rhinitis-induced nasal congestion: a randomized, double-blind, placebocontrolled trial. Adv Ther. 2009;26:795-804.

37. Yamada J, Hamuro J, Hatanaka H, Hamabata K, Kinoshita S. Alleviation of seasonal allergic symptoms with superfine beta-1,3-glucan: a randomized study. J Allergy Clin Immunol. 2007;119:1119-26.

38. Nagakura T, Matsuda S, Shichijyo K, Sugimoto H, Hata K. Dietary supplementation with fish oil rich in omega-3 polyunsaturated fatty acids in children with bronchial asthma. Eur Respir J. 2000;16:861-5.

39. Sarinho E, Medeiros D, Schor D, Rego Silva A, Sales V, Motta ME, et al. Production of interleukin-10 in asthmatic children after Beta-1-3-glucan. Allergol Immunopathol (Madr). 2009;37:188-92.

40. Bener A, Ehlayel MS, Bener HZ, Hamid Q. The impact of vitamin D deficiency on asthma, allergic rhinitis and wheezing in children: an emerging public health problem. J Family Community Med. 2014;21:154-61.

41. van den Elsen L, Garssen J, Willemsen L. Long chain N-3 polyunsaturated fatty acids in the prevention of allergic and cardiovascular disease. Curr Pharm Des. 2012;18:2375-92.

42. Serhan CN, Chiang N, Van Dyke TE. Resolving inflammation: dual anti-inflammatory and pro-resolution lipid mediators. Nat Rev Immunol. 2008:8:349-61.

43. Frei $R$, Akdis M, O'Mahony L. Prebiotics, probiotics, synbiotics, and the immune system: experimental data and clinical evidence. Curr Opin Gastroenterol. 2015;31:153-8.

44. Kawashima S, Hirose K, Iwata A, Takahashi K, Ohkubo A, Tamachi T, Ikeda K, Kagami S, Nakajima H. beta-glucan curdlan induces IL-10-producing CD4+ T cells and inhibits allergic airway inflammation. J Immunol. 2012;189:5713-21.

45. Wang SB, Deng YQ, Ren J, Xiao BK, Liu Z, Tao ZZ. Exogenous interleukin-10 alleviates allergic inflammation but inhibits local interleukin-10 expression in a mouse allergic rhinitis model. BMC Immunol. 2014;15:9.

46. Gehring U, Heinrich J, Hoek G, Giovannangelo M, Nordling E, Bellander T, Gerritsen J, de Jongste JC, Smit HA, Wichmann HE, et al. Bacteria and mould components in house dust and children's allergic sensitisation. Eur Respir J. 2007;29:1144-53.

47. Lai CK, Beasley R, Crane J, Foliaki S, Shah J, Weiland S. Global variation in the prevalence and severity of asthma symptoms: phase three of the International Study of Asthma and Allergies in Childhood (ISAAC). Thorax. 2009;64:476-83.

48. Barreto ML R-SR, Malta DC, Oliveira-Campos M, Andreazzi MA, Cruz AA. Prevalence of asthma symptoms among adolescents in Brazil: National Adolescent School-based Health Survey (PeNSE 2012). Rev Bras Epidemiol Suppl PeNSE. 2014;17(1):106-15. SUPPL PeNSE.

49. Lander RL, Lander AG, Houghton L, Williams SM, Costa-Ribeiro H, Barreto DL, Mattos AP, Gibson RS. Factors influencing growth and intestinal parasitic infections in preschoolers attending philanthropic daycare centers in Salvador, Northeast Region of Brazil. Cad Saude Publica. 2012;28:2177-88.

50. Muniz PT, Ferreira MU, Ferreira CS, Conde WL, Monteiro CA. Intestinal parasitic infections in young children in Sao Paulo, Brazil: prevalences, temporal trends and associations with physical growth. Ann Trop Med Parasitol. 2002;96:503-12.

51. Benicio MH, Ferreira MU, Cardoso MR, Konno SC, Monteiro CA. Wheezing conditions in early childhood: prevalence and risk factors in the city of Sao Paulo, Brazil. Bull World Health Organ. 2004;82:516-22.

52. Hagel I, Puccio F, Lopez E, Lugo D, Cabrera M, Di Prisco MC. Intestinal parasitic infections and atopic dermatitis among Venezuelan Warao Amerindian pre- school children. Pediatr Allergy Immunol. 2014;25:276-82.

53. Akpan A, Morgan R. Oral candidiasis. Postgrad Med J. 2002;78:455-9.
54. Hannula J, Saarela M, Jousimies-Somer H, Takala A, Syrjanen R, Kononen E, Asikainen S. Age-related acquisition of oral and nasopharyngeal yeast species and stability of colonization in young children. Oral Microbiol Immunol. 1999;14:176-82.

55. Berdicevsky I, Ben-Aryeh H, Szargel R, Gutman D. Oral Candida in children. Oral Surg Oral Med Oral Pathol. 1984;57:37-40.

56. Ribeiro TC, Costa-Ribeiro Jr H, Almeida PS, Pontes MV, Leite ME, Filadelfo LR, Khoury JC, Bean JA, Mitmesser SH, Vanderhoof JA, Scalabrin DM. Stool pattern changes in toddlers consuming a follow-on formula supplemented with polydextrose and galactooligosaccharides. J Pediatr Gastroenterol Nutr. 2012:54:288-90.

57. Bongers ME, de Lorijn F, Reitsma JB, Groeneweg M, Taminiau JA, Benninga MA The clinical effect of a new infant formula in term infants with constipation: a double-blind, randomized cross-over trial. Nutr J. 2007;6:8.

58. de Onis M, Onyango AW, Borghi E, Garza C, Yang H. Comparison of the World Health Organization (WHO) child growth standards and the national center for health statistics/WHO international growth reference: implications for child health programmes. Public Health Nutr. 2006;9:942-7.

59. Ghisolfi J, Fantino M, Turck D, de Courcy GP, Vidailhet M. Nutrient intakes of children aged 1-2 years as a function of milk consumption, cows' milk or growing-up milk. Public Health Nutr. 2013;16:524-34.

60. Walton J, Flynn A. Nutritional adequacy of diets containing growing up milks or unfortified cow's milk in Irish children (aged 12-24 months). Food Nutr Res. 2013;57:21836.

61. More S, Shivkumar VB, Gangane N, Shende S. Effects of iron deficiency on cognitive function in school going adolescent females in rural area of central India. Anemia. 2013;2013:819136.

62. Shay NF, Mangian HF. Neurobiology of zinc-influenced eating behavior. J Nutr. 2000;130:1493S-9S.

63. Monteiro CA SS, Mondini L. Secular trends in child anemia in S. Paulo city, Brazil (1984-1996). Rev Saude Publica. 2000;34(6):62-72.

64. de Novaes Oliveira M, Martorell R, Nguyen P. Risk factors associated with hemoglobin levels and nutritional status among Brazilian children attending daycare centers in Sao Paulo City, Brazil. Arch Latinoam Nutr. 2010;60:23-9.

\section{Submit your next manuscript to BioMed Central and we will help you at every step:}

- We accept pre-submission inquiries

- Our selector tool helps you to find the most relevant journal

- We provide round the clock customer support

- Convenient online submission

- Thorough peer review

- Inclusion in PubMed and all major indexing services

- Maximum visibility for your research

Submit your manuscript at www.biomedcentral.com/submit
C) Biomed Central 